\title{
Pedagogical Agents in an Adaptive E-learning System
}

\author{
Aqeel M. Ali. Hussein, Humam K. Majeed Al-Chalabi \\ Automatics Computers and Electronics Faculty, University of Craiova, Craiova, Romania
}

\begin{abstract}
The pedagogical agents for e-learning can immensely help in improving the quality of teaching, evaluating and learning the process through appropriate pedagogical agents. The pedagogical agents for adaptive e-learning systems are basically designed to provide a unique and personal experience to such students who come from diverse backgrounds having different styles of learning and with various educational needs. This study basically discusses the importance of pedagogical approach for the adaptive elearning systems. The selection of personalised (relevant) pedagogical agent can increase the effectiveness of adaptive e-learning, in the form of learning activities, delivered content, and communication. This will lead individuals to an adaptive pedagogical guided e-learning experience in which pedagogy will be the centerpiece, and in which the adaptive power will influence the pedagogy effectiveness. Thus, the main aim of this study is to discuss the importance of pedagogical agents in adaptive e-learning systems and to discuss different approaches of pedagogy including the constructivist approach, collaborative approach, inquiry-based approach, integrative approach, reflective approach, objectivist approach, and competency-based approach.
\end{abstract}

Keywords-pedagogy, pedagogical principles, agents, e-learning, e-learning system, pedagogical agents

DOI: $10.18421 /$ SAR31-04

https://doi.org/10.18421/SAR31-04

Corresponding author: Humam K.Majeed Al-Chalabi, Automatics Computers and Electronics Faculty, University of Craiova, Craiova, Romania.

Email: hemoomajeed@gmail.com

Received: 20 February 2020.

Revised: 12 March 2020.

Accepted: 20 March 2020.

Published: 30 March 2020.

(cc) BY-NC-ND (C) 2020 Aqeel M. Ali. Hussein, Humam K. Majeed Al-Chalabi; published by UIKTEN. This work is licensed under the Creative Commons Attribution NonCommercial - NoDerivs 3.0 License.

The article is published with Open Access at www.sarjournal.com

\section{Introduction}

The pedagogical agents for e-learning can immensely help in improving the quality of teaching, evaluating and learning processes [1]. These agents for adaptive e-learning systems are basically designed to provide a unique and personal experience to such students who come from diverse backgrounds having different styles of learning and with various educational needs [2]. Thus, the main aim of these agents is to identify such differences and convert them into relevant training and content processes which can be easily adopted by each and every student.

The concept of the pedagogical agent is taken from artificial intelligence and computer science and is applied to e-learning systems [3]. It provides a human interface simulation experience between the content and the learner in an adaptive e-learning environment. A pedagogical agent basically involves a model that supports interaction between learner and another person on screen [4].

However, the research on e-learning in recent years has one constant explicit finding that the pedagogical approach is the most fundamental and essential approach for achieving success in a course and should be implemented first and foremost while constructing an e-learning platform [5]. The adaptive e-learning systems should support in making accurate selection of the pedagogical approaches, and then implement the adopted approach on the pedagogical agents to provide an enhanced learning experience[6].

\section{A. Background}

Basically, the access for adaptive e-learning technique is based on the mechanism of content retrieval depending on the prior knowledge and personal user's preferences. However, most of the elearning platforms do not consider the pedagogical agents in terms of narrative, structure, and presentation purposes or in some cases it is very weakly incorporated in the system [7]. In those elearning systems where pedagogical agents are 
incorporated, it is embedded inherently in the learning structure which makes it quite complex to reuse or to implement other forms of pedagogical approach in the same adaptive e-learning system [8]. Therefore, due to the problem of inflexibility in the learning design, it is essential to address various pedagogical approaches that must be identified and considered in order to develop an effective adaptive e-learning system [9].

This study basically discusses the importance of pedagogical agents in terms of various pedagogical approaches for adaptive e-learning systems. The selection of personalised (relevant) pedagogical agents can increase the effectiveness of adaptive elearning, in the form of learning activities, delivered content, and communication [10]. This will lead individuals to an adaptive pedagogical guided elearning experience in which pedagogy will be the centrepiece, and in which the adaptive power will influence the pedagogy effectiveness [11].

\section{B. Aim and Objectives}

While e-learning gives more advantage of online access to the students around the world, some drawbacks mostly from the pedagogy perspective confine the major benefits [12]. It is not possible to treat all learners equally in a wide range of e-learning students. Some students may have different backgrounds or have lower prior knowledge, preferences, interests and learning styles, therefore, the approach of "one size fits all" cannot be implemented here. Thus an adaptive e-learning system along with an appropriate pedagogical agent is highly required [13].

Thus, the main aim of this study is to discuss the importance of pedagogical agents in adaptive elearning systems and to discuss different approaches of pedagogy including the constructivist approach, collaborative approach, inquiry-based approach, integrative approach, reflective approach, objectivist approach, and competency-based approach.

\section{Research Question}

To achieve the basic research objective, it is essential to investigate the answer of the following question;

What are the major pedagogical approaches that can be implemented for the adaptive e-learning system?

\section{Literature Review}

This section presents a thorough review of literature about pedagogical agents that can utilise various approaches that can be implemented to enhance adaptive e-learning.
Implementing and planning e-learning courses face many pedagogical problems. An adaptive e-learning system is basically enforced by different factors such as motivation, attention, and emotions, and characteristics like cognitive styles, prior knowledge, constitutional states, intellectual performance, and so forth [14]. Thus, from these characteristics, one can say that adaptive e-learning is very much dependent on the learner as well. Therefore, the developers of elearning content must have prior knowledge about different pedagogical approaches and should support a wide range of techniques to provide the different types of learners the best e-learning experience [15].

The development of pedagogical agents is closely related to that of digital animation. As the animation made in computers gained progress, it was quickly adopted by the educating firms in order to enhance the system of e-learning experience [16]. However, initially the pedagogical agent was shown in the form of cartoon as in MS Word and other applications. A constructivist approach of pedagogy is a theory that is based on the idea of how students know what they know [17]. The solving of an issue is present at the heart of development thinking and learning. A constructivist theory can be understood from the perspective of both psychology and philosophy [18]. The significance of this theory is that the students develop their own meaning and knowledge through their adaptive e-learning systems [19]. Constructivist theory significantly emphasises upon learners working in groups in order to get engaged in the elearning experience. This can immensely help students who come from diverse cultures and backgrounds [20]. Such theory influences intellectual, social and communication collaboration. Constructivist theory is different from those traditional theories which are based on e-learners develop their own skills by working alone. The constructivist theory encourages adaptive e-learning experience through different factors such as experimentation, group discussions, and research projects [21]. Platforms like discussion forums can help learners a lot to solve their queries quickly. However, the support systems like online toolkits can help in adaptive e-learning by informing and guiding users for different activities which thus, enable the principle of constructivism. Also, access to different e-learning expertise and resources influences the creation of more student-centred and authentic adaptive e-learning conditions [22].

The collaborative approach for adaptive e-learning can be significant in a number of ways. The development of both the adaptive e-learning system and the constructivism approach has led to the formation of a specific type of constructivist learning called collaborative approach [23]. A pedagogical collaborative approach presents a learning model in 
which learners from diverse background are supported and encouraged to work in groups in order to enhance knowledge and to explore to seek the concept of learning required to solve the given problem rather than relying on what an individual thinks is the correct answer [24]. Although the collaborative theory for adaptive e-learning agents' influences the students to get engaged and be active, still it is not considered as sufficient for knowledge or learning development.

The inquiry-based pedagogical approach involves the need for learner's role in the adaptive learning process [25]. It provides opportunity for students to explore the provided resources, share their ideas, and ask questions. It basically builds a sense of encouragement in the e-learners especially those who come from diverse backgrounds [26]. The inquirybased approach involves different techniques to boost the adaptive e-learning experience through guided learning and group discussions. Thus, instead of remembering different facts and figures, it facilitates students to learn something new by doing things by themselves. This helps in building knowledge through discussion, experience and exploration [27].

The integrative pedagogical approach links elearning education with real-life applications. It helps in bringing the relevancy and meaningfulness of a topic in the mind of the students. Thus, the students begin to learn with an aim in their mind, which eventually improves the understanding of the subject's knowledge [28]. An integrative approach is basically a theory of learning which attracts students toward integrative learning subjects and helps individuals to inter-link across the curriculum. Integrative learning experience helps in bringing the traditional learning resources together in order to bring a more authentic way of understanding for the e-learning students [29]. An integration pedagogy has four main objectives. The first is developing a learning sense in students with diversity. This can be achieved by presenting the process of learning with a meaningful knowledge context that develops a sense to learners in terms of real-life scenarios that they may face in the future. The second is differentiating between relevant and irrelevant matters. In any elearning system it is very important that the developer must focus only on providing relevant resources that can be considered practical and necessary for student's daily life or those materials which can aid in future learning process. The third is implementing theoretical learning practically. It basically means that it is not good to fill the minds of students only with knowledge, but guiding them about the values, principles, and how to become a responsible individual is also important. The fourth is associating the elements of learning. It basically interlinks the above three objectives of integrative approach. It involves providing individuals the capacity to use their own learnings and skills in order to deal with the daily issues, even those which are unexpected [30].

The reflective pedagogical approach basically helps in improving the adaptive e-learning system. It is a mechanism in which the creator or developer of the e-learning platforms think how the practices of online teaching can be improved [31]. It basically helps in analysing how the course can be taught efficiently or what can be altered or improved in order to achieve higher outcomes from the learning processes. Some important components of the reflective approach may include what is being implemented currently, why it is implemented, and how much the student is gaining benefits from their adaptive e-learning experience. Any individual can adopt the reflective approach in order to learn about their own actions and to assess their own practices (for example cooperative way of learning or Group learning process) or to focus upon such problems that are regularly encountered by the students during the e-learning process [32].

The objectivist approach relates to active student engagement in the learning process. This approach helps in encouraging students to study [33]. However, this theory does not support that students construct or transform the truth, knowledge or reality reasons. The objectivist theory is basically the opposite of the constructivist theory [34]. Objectivism relates to the perception of the nature of the study and the importance of knowing something. Objectivism is based on evidence (including logical implications, relevant facts, and figures, human perceptions) to improve students' e-learning experience. This approach is quite essential in the decision making process [35]. It defines the learning objectives and assumes that the individual is a hollow vessel that must be filled by the pedagogical agent.

A competency-based pedagogical approach targets the student's illustrations of the required outcomes of learning as central to the process of learning [36]. It is mainly concerned with the progression of students' learning pace after they adapt the e-learning system. It is important for the developers to create pedagogical agents keeping in mind the talent and skill levels of majority of the students, and their ability to perform a given task. The competencybased approach may involve two types of competencies, namely behaviour-based and workbased competencies. Competencies related to work refer to specific skills needed for learning such as language fluency, or ability to work on various software. While the competency of behaviour refers to the individual characteristics including motivation, attitude, and interpersonal skills [37]. 


\section{Discussion}

The pedagogical agents can be used in the form of frameworks and models in the adaptive e-learning system. These frameworks and models can be utilised for guiding purpose to enhance the process of design for student learning activities and to improve the environment of learning. It aids in guiding the learners especially those who need higher attention due to their diverse background and assist them through the process of learning. It also provides a mean through which the professionals involved in the adaptive e-learning process can modify and review their practices [38].

The pedagogical agents are very useful especially for e-learning because through this technology the educating professionals can reach students from around the world in new and better ways. It further adds a deeper abstraction level in the process of learning. These agents can help individuals to understand what a specific form of abstraction means and looks like, and how can an e-learning institute or organisation succeed in learning and teaching online. These pedagogical agents have certain benefits for the students associated with the e-learning process, including enhancing experience of learning, improving teaching and learning skills, fostering candidates' curiosity, deeper understanding on the subject, allowing individual students to own the learning process, enhancing engagement in the subject learning, and creating a passion for learning [23].

In order to develop an adaptive online experience for students, several key factors must be considered based on the pedagogical approach. Firstly, the objectives and goals of the course must be identified. These objectives and goals will develop the requirement base and an initial scale for evaluation that will help in conducting the evaluation process. Once the specific objective and goal are identified, a pedagogical approach based on the course must be implemented. After that, a domain of knowledge in which the course content will reside must be developed. Once the learning area is elaborated and identified, it can be applied in accordance with the selected pedagogical approach [39].

\section{A. Opportunities and Challenges}

The task of developing an adaptive e-learning environment is quite difficult. In order to develop a student-centred e-learning environment, the developers required to understand which students are involved in the learning process, and how they adapt the learning strategy, from being attentive towards the subject to the form of support they require, and to honour the role of the student in the process of learning [40]. In the e-learning field the number of students being drawn is increasing every day. According to studies, most of the students who are attracted towards this field are no longer adults, but a great number of younger generation is also attracted towards adaptive e-learning. Thus, due to this fact many students belonging from different race, cultures, and languages enroll the adaptive e-learning process. A great number of institutions which deliver courses that involve blended models of learning, which a combination of e-learning is, and face-toface learning processes have also shown interest in the field of e-learning system. As mentioned before, a pedagogical approach is very important for adaptive e-learning process, without such approach a number of challenges can be experienced by both students and the developers. Especially students face many challenges such as cultural and learning style challenges. Since every individual student has their own style of learning which can be influenced through their culture, thus those students who are provided online studying resources by keeping in mind their style of learning and taking their cultural aspects into considerations, will perform much better as compared to other students who lack implementation of pedagogical approach [41]. In order to obtain good learning outcome, it is important to have an understanding of student style of learning as e-learning platforms that lack pedagogical approaches are not able to understand student's style of learning clearly due to lack of constructive, interactive, and reflective pedagogical agents. Due to this reason the students are enforced to learn from audio instructions, visual presentations, or through exhaustive lecture notes. According to a study, many instructors and teachers are against the e-learning systems, they believe that when the e-learning systems lack pedagogical agents they leave a majority of students behind, especially those from diverse backgrounds [41]. They think that e-learning systems have a very limited personalisation scope and thus if learners are not capable to master a subject they may lose motivation quite easily. Also, an adaptive e-learning experience can be expensive. However, forming an adaptive learning environment does not only depend on cost but also requires correct skills. E-learning institutions are required to recruit a team of creators who can mould the Elearning system into adaptive learning system by the implementation of different pedagogical theories. Another major challenge faced by students while dealing with an adaptive learning approach is how to perform analysis of the given data. It basically depends on the prior knowledge of the students, due to lack of knowledge the patterns, graphs, facts, and figures provided at their disposal might not help them [42]. Some other common challenges faced by 
students who are trying to enroll in adaptive elearning process include the inability of internet access, funds limitation, inadequate policy, and lack of staff training.

\section{Future Implications}

Around the world, there is a number of challenges of innovative e-learning design which are mostly oldfashioned or too rigid due to lack of pedagogical agents. A number of students are disengaging from elearning education or are achieving grades below their potential due to the same reason. The pedagogical approach is essential and will remain to be so. Whether these approaches are utilised in adaptive e-learning environment or traditional learning environment, without such agents the basic need for learning will not be addressed. However, the use of pedagogical agents has greatly evolved over the past decades, and it is envisioned it will bring more changes in the future of the e-learning process. Pedagogical agents might help in embracing AI (Artificial Intelligence), due to rapidly evolving technology the e-learning tools may help students from around the world to succeed in this mission. Although adaptive e-learning systems are not uncommon in today's world, still many students prefer the traditional learning approach. Thus, with the utilisation of pedagogical agents, many future generations may get benefits through adaptive online learning systems. Also, the challenges which are commonly faced by students from diverse backgrounds during the adaptive e-learning process including language issues, racial disparities, and lack of assistance for the disabled students, can be solved through pedagogical agents in future.

\section{Conclusion}

Adaptive e-learning opportunities have brought a number of benefits not only for students but also for institutions, instructors and teachers. Education should be considered as an important contributor to the world's population, rather than making it better from others. Adaptive e-learning systems enable students to learn at their own personal pace. Through pedagogical agents, students from diverse backgrounds are able to learn better than ever before. Still, the e-learning system brings its own set of challenges and benefits at the same time.

An adaptive e-learning does not only involve adaptive content construction and retrieval, but it is also a blend of adaptivity, domain knowledge, and pedagogy. Thus, with adaptations of such agents and systems, e-learning can surely prove as an essential tool for learning for the generations to come.

\section{References}

[1] Apostol, S., ŞOICA, O., Manasia, L., \& Ştefan, C. (2013). Virtual Pedagogical Agents in the Context of Virtual Learning Environments: Framework and Theoretical Models. eLearning \& Software for Education, (2).

[2] Bendou, A., Abrache, M. A., \& Cherkaoui, C. (2017, October). Contribution of pedagogical agents to motivate learners in online learning environments: the case of the PAOLE agent. In Proceedings of the Mediterranean Symposium on Smart City Applications (pp. 344-356). Springer, Cham.

[3] Ballera, M., \& Elssaedi, M. M. (2012, October). Incorporating Social Oriented Agent and Interactive Simulation in E-learning: Impact on Learning, Perceptions, Experiences to non-Native English Students. In E-Learn: World Conference on ELearning in Corporate, Government, Healthcare, and Higher Education (pp. 495-503). Association for the Advancement of Computing in Education (AACE).

[4] Alexandru, A., Tirziu, E., Tudora, E., \& Bica, O. (2015). Enhanced education by using intelligent agents in multi-agent adaptive e-learning systems. Studies in Informatics and Control, 24(1), 13-22. doi: 10.24846/v24i1y201502.

[5] Angeli, C., Mavroudi, A., \& Christodoulou, A. (2015, March). e-TPCK: An Adaptive E-Learning Technology for the Development of Teachers' Technological Pedagogical Content Knowledge. In Society for Information Technology \& Teacher Education International Conference (pp. 3059-3064). Association for the Advancement of Computing in Education (AACE).

[6] Apostol, S., Sofronia, A., Mihailescu, D., \& Petrescu, L. (2012, July). One size does not fit all! A theoretical model for adaptive tutoring systems. In The International Scientific Conference eLearning and Software for Education (Vol. 2, p. 44). " Carol I" National Defence University. doi: 10.5682/2066026x-12-098.

[7] Chatzara, K., Karagiannidis, C., \& Stamatis, D. (2016). Cognitive support embedded in self-regulated e-learning systems for students with special learning needs. Education and Information Technologies, 21(2), 283-299. doi: 10.1007/s10639-014-9320-1.

[8] Bennane, A. (2013). Adaptive educational software by applying reinforcement learning. Informatics in Education-An International Journal, 12(1), 13-27.

[9] Daradoumis, T., Bassi, R., Xhafa, F., \& Caballé, S. (2013, October). A review on massive e-learning (MOOC) design, delivery and assessment. In 2013 eighth international conference on $P 2 P$, parallel, grid, cloud and internet computing (pp. 208-213). IEEE. doi: 10.1109/3PGCIC.2013.37.

[10] Bokhari, M. U., \& Ahmad, S. (2014, October). Multiagent based e-learning systems: a comparative study. In Proceedings of the 2014 international conference on information and communication technology for competitive strategies (pp. 1-6). doi: $10.1145 / 2677855.2677875$. 
[11] Ghadirli, H. M., \& Rastgarpour, M. (2013). A Model for an Intelligent and Adaptive Tutor based on Web by Jackson's Learning Styles Profiler and Expert Systems. arXiv preprint arXiv:1304.4045.

[12]M. Ivanovic and L. Jain.(2014). E-Learning Paradigms and Applications, vol. 528. Berlin, Heidelberg: Springer Berlin Heidelberg.

[13]Fardinpour, A., Pedram, M. M., \& Burkle, M. (2014). Intelligent learning management systems: Definition, features and measurement of intelligence. International Journal of Distance Education Technologies (IJDET), 12(4), 19-31. doi: 10.4018/ijdet.2014100102.

[14] Hammami, S., \& Mathkour, H. (2015). Adaptive elearning system based on agents and object petri nets (AELS-A/OPN). Computer applications in engineering education, 23(2), 170-190. doi: 10.1002/cae.21587.

[15] Herlo, D. (2012). Adaptive learning influence in education. Educația Plus, 8(2), 142-151.

[16] Ivanović, M., Mitrović, D., Budimac, Z., Vesin, B., \& Jerinić, L. (2012, September). Different roles of agents in personalized programming learning environment. In International Conference on WebBased Learning (pp. 161-170). Springer, Berlin, Heidelberg. doi: 10.1007/978-3-662-43454-3_17.

[17] Khamparia, A., \& Pandey, B. (2015). Knowledge and intelligent computing methods in elearning. International Journal of Technology Enhanced Learning, 7(3), 221-242. doi: 10.1504/IJTEL.2015.072810.

[18] Kamsa, I., Elghibari, F., Elouahbi, R., Chehbi, S., \& El Khoukhi, F. (2015, June). Learning time planning in a distance learning system using intelligent agents. In 2015 International Conference on Information Technology Based Higher Education and Training (ITHET) (pp. 1-4). IEEE. doi: 10.1109/ITHET.2015.7218027.

[19] Ivanović, M., Mitrović, D., Budimac, Z., Jerinić, L., \& Bădică, C. (2015). HAPA: Harvester and pedagogical agents in e-learning environments. International journal of computers communications \& control, 10(2), 200-210. doi: 10.15837/ijccc.2015.2.1753.

[20] Jawahar, S., \& Nirmala, K. (2015). Quantification of learner characteristics for collaborative agent based elearning automation. Indian Journal of Science and Technology, 8(14), 1-6. doi: $10.17485 / \mathrm{ijst} / 2015 / \mathrm{v} 8 \mathrm{i} 14 / 73119$.

[21] Melesko, J., \& Kurilovas, E. (2016, November). Personalised intelligent multi-agent learning system for engineering courses. In 2016 IEEE 4th Workshop on Advances in Information, Electronic and Electrical Engineering (AIEEE) (pp. 1-6). IEEE. doi: 10.1109/AIEEE.2016.7821821.

[22] Kim, J., Seok, Y., Lee, D., \& Lee, H. (2012, January). A motivational thermostat framework for enhanced Elearning systems. In 2012 45th Hawaii International Conference on System Sciences (pp. 3-10). IEEE. doi: 10.1109/HICSS.2012.67.
[23] Kim, J., Seok, Y., Lee, D., \& Lee, H. (2012, January). A motivational thermostat framework for enhanced Elearning systems. In 2012 45th Hawaii International Conference on System Sciences (pp. 3-10). IEEE.

[24] Mavroudi, A., \& Hadzilacos, T. (2016). Historical Overview of Adaptive e-learning Approaches Focusing on the Underlying Pedagogy. In State-ofthe-Art and Future Directions of Smart Learning (pp. 115-121). Springer, Singapore. doi: 10.1007/978-981-287-868-7 13.

[25] Kurilovas, E., Kubilinskiene, S., \& Dagiene, V. (2014). Web 3.0-Based personalisation of learning objects in virtual learning environments. Computers in Human Behavior, 30, 654-662. doi: 10.1016/j.chb.2013.07.039.

[26] Sadakathulla, P. K. (2014). Artificial Intelligence in E learning Using Pedagogical Software Agents. International Journal of Advanced Research in Computer Science and Software Engineering, 4(11), 578-581.

[27] Musumba, G. W., Oboko, R. O., \& Nyongesa, H. O. (2013). Agent-based adaptive e-learning model for any learning management system. International Journal of Machine Learning and Applications, 2(1), 9. doi: 10.4102/ijmla.v2i1.6.

[28] Ostrow, K. S., Schultz, S. E., \& Arroyo, I. (2014). Promoting Growth Mindset Within Intelligent Tutoring Systems. In EDM (Workshops).

[29] Poitras, E. G., \& Lajoie, S. P. (2014). Developing an agent-based adaptive system for scaffolding selfregulated inquiry learning in history education. Educational Technology Research and Development, 62(3), 335-366. doi: 10.1007/s11423014-9338-5.

[30] Shute, V. J., \& Zapata-Rivera, D. (2012). Adaptive educational systems. Adaptive technologies for training and education, 7(27), 1-35. doi: 10.1017/CBO9781139049580.004.

[31] Warner, T. (2012). E-coaching systems: Convenient, anytime, anywhere, and nonhuman. Performance Improvement, 51(9), 22-28. doi: 10.1002/pfi.21305.

[32] Sottilare, R., \& Goldberg, B. (2012). Designing adaptive computer-based tutoring systems to accelerate learning and facilitate retention. Cognitive Technology, 17(1), 19-33.

[33] Wong, L. H., \& Looi, C. K. (2012). Swarm intelligence: new techniques for adaptive systems to provide learning support. Interactive Learning Environments, 20(1), 19-40. doi: 10.1080/10494821003714681.

[34] Utomo, A. Y., \& Santoso, H. B. (2015, April). Development of gamification-enriched pedagogical agent for e-learning system based on community of inquiry. In Proceedings of the International HCI and UX Conference in Indonesia (pp. 1-9). doi: 10.1145/2742032.2742033.

[35] Truong, H. M. (2016). Integrating learning styles and adaptive e-learning system: Current developments, problems and opportunities. Computers in human behavior, 55, 1185-1193. doi: $10.1016 /$ j.chb.2015.02.014. 
[36] G. Veletsianos and G. S. Russell.(2014). Pedagogical Agents, in Handbook of Research on Educational Communications and Technology, New York, NY: Springer New York, 759-769.

[37] Andrews, R., \& Haythornthwaite, C. (Eds.). (2007). The Sage handbook of e-learning research. Sage.

[38] Goyal, M., \& Krishnamurthi, R. (2019). Pedagogical Software Agents for Personalized E-Learning Using Soft Computing Techniques. In Nature-Inspired Algorithms for Big Data Frameworks (pp. 319-338). IGI Global.

[39] Maryadi, J. A., Santoso, H., \& Isa, Y. K. (2017, November). Development of Personalized Pedagogical Agent for Student-Centered e-Learning Environment. In 2017 7th World Engineering Education Forum (WEEF) (pp. 309-314). IEEE. doi: 10.1109/WEEF.2017.8467028.
[40] Salehi, V., \& Teymouri Nia, F. (2019). Effect of levels of realism of mobile-based pedagogical agents on health e-learning. Future of Medical Education Journal, 9(2), 40-45. doi: 10.22038/FMEJ.2019.39824.1261.

[41]Daniels, B., \& Conley, Q. (2015, October). Using Pedagogical Agents to Create Engaging, Personalized E-Learning. In E-Learn: World Conference on ELearning in Corporate, Government, Healthcare, and Higher Education (pp. 1754-1757). Association for the Advancement of Computing in Education (AACE).

[42] Bhattacharya, S., Chowdhury, S., \& Roy, S. (2017). Enhancing Quality of Learning Experience Through Intelligent Agent in E-Learning. International Journal of Uncertainty, Fuzziness and Knowledge-Based Systems, 25(01), 31-52. doi: $10.1142 / \mathrm{S} 0218488517500027$. 